\title{
Solution and Solid-State Emission Toggling of a Photochromic Hy- drazone
}

\author{
Baihao Shao, ${ }^{+, \#}$ Massimo Baroncini, ${ }^{,, \S, \#}$ Hai Qian, ${ }^{+, \#}$ Laura Bussotti, ${ }^{\|, \perp}$ Mariangela Di Donato, ${ }^{\|, \perp}$ Alberto Credi, \\ $\neq, \S, *$ Ivan Aprahamian ${ }^{\dagger, *}$ \\ ${ }^{+}$Department of Chemistry, Dartmouth College, Hanover, New Hampshire 03755, United States \\ ‡ Center for Light Activated Nanostructures (CLAN), Università di Bologna and Consiglio Nazionale delle Ricerche, via Gobetti 101, \\ 40129 Bologna, Italy \\ ${ }^{\mathbb{S}}$ Dipartimento di Scienze e Tecnologie Agro-alimentari, Università di Bologna, viale Fanin 50, 40127 Bologna, Italy \\ " LENS - European Laboratory for Non-linear Spectroscopy, via N. Carrara 1, 50019 Sesto Fiorentino (FI), Italy \\ ${ }^{\perp}$ INO - Istituto Nazionale di Ottica, Largo Enrico Fermi 6, 50125 Firenze, Italy
}

Supporting Information Placeholder

\begin{abstract}
The proliferation of light-activated switches in recent years has enabled their use in a broad range of applications encompassing an array of research fields and disciplines. All current systems, however, have limitations (e.g., from complicated synthesis to incompatibility in biologically relevant media and lack of switching in the solid-state) that can stifle their real-life application. Here we report on a system that packs most, if not all, the desired, targeted and sought-after traits from photochromic compounds (bistability, switching in various media ranging from serum to solid-state, while exhibiting ON/OFF fluorescence emission switching, and two-photon assisted near infrared light toggling) in an easily accessible structure.
\end{abstract}

Photochromic compounds ${ }^{1}$ play a key role in diverse areas of science and technology as they enable the control over (bio)molecular processes, ${ }^{2}$ properties, assemblies, and functions ${ }^{3}$ with the high temporal and spatial resolution of light. These capabilities have allowed for their incorporation in responsive materials and surfaces, ${ }^{4}$ catalysis and separation, ${ }^{5}$ information storage, ${ }^{6}$ energy conversion, ${ }^{7}$ and drug design, ${ }^{8}$ and have made them an integral part of the field of artificial molecular switches and machines. ${ }^{9} \mathrm{Sev}-$ eral prominent photoswitches have been investigated throughout the years (e.g., azobenzenes, ${ }^{10}$ diarylethenes, ${ }^{11}$ spiropyrans, ${ }^{12}$ and fulgides ${ }^{13}$ ) and while great strides have been made in their development, optimization, and use, a few drawbacks hinder their deployment in real-life applications. Depending on the system, these shortcomings include complicated synthesis, low thermal and/or photochemical stability, undesired spectral features (e.g., UV light activation), inefficient photoconversion, lack of solid-state switching and/or fluorescence emission, small amplitude geometrical changes, $\mathrm{pH}$ and/or oxygen sensitivity, reduction by glutathione, and more commonly inadequate (if any) switching in aqueous media.

Considering the prevalent and prospective use of photochromic compounds in a broad range of fields and disciplines, the development of new systems that can overcome some, if not all these short- comings is a sought-after goal. This necessity explains the surge witnessed in the past decade in the development of new photochromic compounds, ${ }^{14}$ with an emphasis on visible-light activated ones. $^{15}$

a)

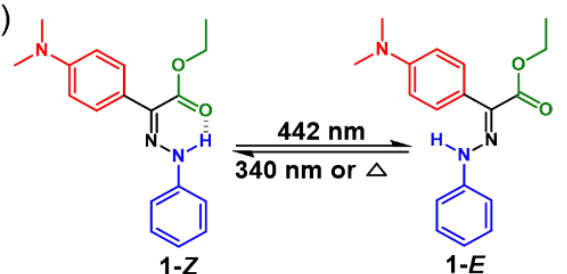

b)

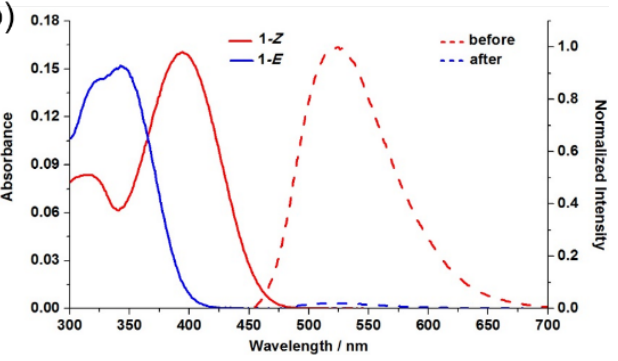

Figure 1. (a) Light induced $E / Z$ isomerization of hydrazone 1; (b) Solid lines: UV-Vis spectra $\left(1.0 \times 10^{-5} \mathrm{M}\right)$ of $\mathbf{1}-Z$ and $\mathbf{1}-E$ isomers in toluene; Dashed lines: Fluorescence emission spectra $\left(5.0 \times 10^{-6} \mathrm{M} ; \lambda_{\mathrm{ex}}\right.$ $=420 \mathrm{~nm}$ ) of $\mathbf{1}$ in toluene, before (red) and after irradiation (blue).

As part of our effort to address the drawbacks associated with photochromic compounds, ${ }^{16}$ we report here on an easy-to-make, robust, bistable, hydrazone-based ${ }^{17}$ photochromic compound (1) whose completely new functions and properties in organic solutions, which include fluorescence ON/OFF switching under both 1-photon and 2-photon excitation (i.e., near infrared (NIR) light), are maintained in serum, and are transferable to the solid-state! This compound combines together the most significant properties of widely used photoswitches (i.e., the large geometrical changes of azobenzenes, the bistability and solid-state switching of diarylethenes, and the emission toggling of oxazines ${ }^{18}$ and spiropyrans ${ }^{19}$ ) while circumventing their shortcomings (e.g., reduction 
with glutathione, complicated synthesis, low photochemical stability, switching in water, etc.).

Table 1. Photophysical and photochemical properties of $\mathbf{1}$.

\begin{tabular}{lccc}
\hline Parameter & Toluene & Serum & Solid-state \\
\hline$\lambda_{\text {max }, \text { abs }}, Z$-isomer $(\mathrm{nm})$ & 395 & 395 & 395 \\
$\lambda_{\text {max,abs, }}$-isomer $(\mathrm{nm})$ & 343 & 343 & 336 \\
$\lambda_{\text {max }, \mathrm{em},}$, -isomer $(\mathrm{nm})$ & 525 & 525 & 560 \\
$\Phi_{\mathrm{FL}}, Z$-isomer $(\%)$ & $0.7 \pm 0.1$ & $3.5 \pm 0.4$ & $27.5 \pm 1.4^{a}$ \\
$([Z]:[E])_{\mathrm{PSS}}(\%)$ & $>99:<1$ & $96: 4$ & $>90:<10$ \\
$([E]:[Z])_{\mathrm{PSS}}(\%)$ & $82: 18$ & $76: 24$ & $70: 30$ \\
$\Phi_{Z \rightarrow E}(\%)$ & $32.0 \pm 0.9$ & $18.9 \pm 0.8$ & $-{ }^{b}$ \\
$\Phi_{E \rightarrow Z}(\%)$ & $14.7 \pm 1.0$ & $6.9 \pm 0.3$ & $-{ }^{b}$ \\
$\tau_{1 / 2}(\mathrm{y})^{c}$ & $75 \pm 3$ & $-{ }^{d}$ & $-{ }^{b}$
\end{tabular}

${ }^{a}$ Powder Sample. ${ }^{b}$ Not determined (see the SI). ${ }^{c}$ Half life of the thermal $E \rightarrow Z$ transformation. ${ }^{\mathrm{d}}$ Cannot be measured accurately in serum because of ester group hydrolysis at elevated temperatures.

Hydrazone 1 was synthesized as described in Scheme S1 and fully characterized using NMR spectroscopy, mass spectrometry and X-ray crystallography (Figures S2, S3 and S47). An equilibrated solution (Toluene; under dark) of $\mathbf{1}$ shows an absorption maximum $\left(\lambda_{\max }\right)$ at $395 \mathrm{~nm}$ (Figure $1 \mathrm{~b}$ and Table 1), with a molar absorption coefficient $(\varepsilon)$ of $14600 \mathrm{M}^{-1} \cdot \mathrm{cm}^{-1}$. The absorption maximum of $\mathbf{1}-Z$ is shifted bathochromically by $28 \mathrm{~nm}$ compared to a previously reported hydrazone lacking the $\mathrm{NMe}_{2}$ electron donating group $\left(\lambda_{\max }=367 \mathrm{~nm}\right) .{ }^{16 \mathrm{c}}$ Irradiation of the solution of 1 with a 442 nm light source induces a $Z \rightarrow E$ photoisomerization (photostationary state (PSS) of $>99 \% E ; \Phi_{Z \rightarrow E}=32.0 \pm 0.9 \%$; Figure S14), accompanied by the appearance of a new absorption band at $\lambda_{\max }=$ $343 \mathrm{~nm}\left(\varepsilon=13800 \mathrm{M}^{-1} \cdot \mathrm{cm}^{-1}\right)$, and a color change from light yellow to colorless (Figure $1 \mathrm{~b}$ ). The reverse process $(E \rightarrow Z)$ can be triggered by using a $340 \mathrm{~nm}$ light source $\left(\mathrm{PSS}_{340}=82 \% 1-Z ; \Phi_{E \rightarrow Z}\right.$ $=14.7 \pm 1.0 \%$; Figure S15) the system can be cycled between the two isomers by alternating 442 and $340 \mathrm{~nm}$ irradiation (Figures S17 and S18). ${ }^{20}$ The thermal $E \rightarrow Z$ back-isomerization half-life $\left(\tau_{1 / 2}\right)$ at $298 \mathrm{~K}$ was measured to be $75 \pm 3$ years (Figure $S 45$ ).

The introduction of the $\mathrm{NMe}_{2}$ group drastically enhances the emission of the $Z$ isomer compared to the parent system which is not emissive (Figure S36). ${ }^{21}$ Upon excitation with blue light $\left(\lambda_{\mathrm{ex}}=\right.$ $420 \mathrm{~nm}$ ) the toluene solution of $1-Z$ exhibits an intense emission band $\left(\lambda_{\mathrm{em}}\right)$ at $525 \mathrm{~nm}$ (Stokes shift of $130 \mathrm{~nm}$; Figure $\left.1 \mathrm{~b}\right)$. The fluorescence lifetime (Figure S31) and quantum yield of the process were determined to be $193 \pm 2$ ps and $0.7 \pm 0.1 \%$, respectively (Table 1). While this emission quantum yield is lower than in other switchable fluorophores, ${ }^{11,18,19}$ it is still high enough for applications. ${ }^{22}$ Switching 1-Z to 1-E using $442 \mathrm{~nm}$ light leads to quenching of fluorescence. Irradiation of the E-dominant solution with 340 $\mathrm{nm}$ light leads to a $Z$-dominant solution, which turns the emission ON again. Such an ON-OFF fluorescence response in photochromic compounds, especially those that function upon configurational changes, is highly unusual. ${ }^{23}$ The fluorescence modulation can be cycled 10 times with no significant signs of photobleaching (Figure S34).
As part of our solvent screening studies (Figures S19, S38), we found that $\mathbf{1}$ can undergo photoisomerization in fetal bovine serum (FBS) buffer (Figure S19). A solution of 1 in 10\% FBS buffer (PBS with $10 \%$ DMSO, $\mathrm{pH}=7.4$ ) has a $\lambda_{\max }$ at $395 \mathrm{~nm}$, which shifts to $\lambda_{\max }=343 \mathrm{~nm}$ upon isomerization with $442 \mathrm{~nm}$ light $\left(\mathrm{PSS}_{442}=96 \%\right.$ 1-E; $\left.\Phi_{Z \rightarrow E}=18.9 \pm 0.8 \%\right)$. These observations highlight the transformation of the initially present $1-Z$ form into the $E$ isomer. The back $E \rightarrow Z$ isomerization process ( $\mathrm{PSS}_{340}=76 \% 1-Z ; \Phi_{E \rightarrow Z}=$ $6.9 \pm 0.3 \%$ ) can be triggered by irradiating with $340 \mathrm{~nm}$ light, reverting the system to its original state. More interestingly, the emission of $1-Z$ in the serum buffer is maintained ( $\tau=0.59 \pm 0.01 \mathrm{~ns}$ and $\Phi_{\mathrm{FL}}$ $=3.5 \pm 0.4 \%$; Figure S32) with a maximum emission band at $525 \mathrm{~nm}$ $\left(\lambda_{\mathrm{ex}}=420 \mathrm{~nm}\right)$. This behavior is contrary to the diminished fluorescence intensity observed for $1-Z$ in polar protic solvents and aqueous solutions (Figures S19 and S39), most likely because 1-Z interacts with the protein components of the FBS buffer (Figure S22). ${ }^{24}$ The switching in serum prompted us to also test the sensitivity of 1 towards glutathione reduction. We found that $\mathbf{1}$ and its switching process are not affected by GSH (Figure S23).

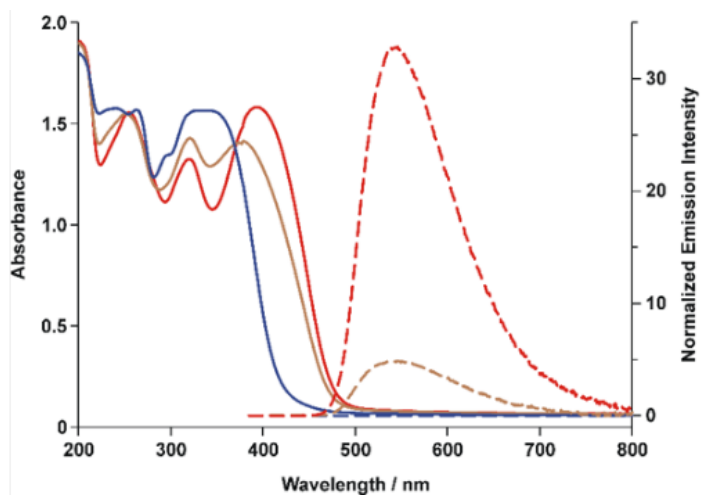

Figure 2. Absorption spectra (solid lines, left scale) and emission spectra (dashed lines, right scale; $\lambda_{\mathrm{ex}}=380 \mathrm{~nm}$ ) of a drop-casted film of $\mathbf{1}$. The red lines are of 1-Z, the blue lines correspond to $\mathrm{PSS}_{450}(>90 \% \mathbf{1}$ $E)$, and the brown lines depict the bands at PSS $_{360}$.

We were pleasantly surprised to find that the photoswitching behavior of $\mathbf{1}$ also takes place in drop-casted films, which is a rare property in molecular switches in general, ${ }^{11}$ and configurational ones in particular. ${ }^{25}$ The absorption and emission spectra $\left(\lambda_{\mathrm{ex}}=380\right.$ $\mathrm{nm}$ ) of $\mathbf{1 - Z}$ in the solid film (Figure 2) are very similar to those recorded in solution (Figure $1 \mathrm{~b}$ ) indicating that the same isomerization process is taking place. Irradiation of the film at $450 \mathrm{~nm}$ brings about absorption spectral changes that are almost identical to those observed in solution, indicating efficient $Z \rightarrow E$ isomerization in the solid-state $\left(\mathrm{PSS}_{450}=>90 \% \mathbf{1}-E\right)$.

Remarkably, the emission $\left(\tau=0.07 \pm 0.01 \mathrm{~ns}\right.$ and $\Phi_{\mathrm{FL}}=$ $27.5 \pm 1.4 \%$; Figure S33) of the $Z$ isomer is maintained in the solidstate (i.e., there is no aggregation-caused quenching), ${ }^{26}$ and so is the toggling between the ON/OFF states, which is also highly uncommon. ${ }^{27}$ The characteristic emission of the $Z$ form is quenched at the photostationary state, confirming that the $1-E$ form is nonemissive also in the solid-state. We hypothesize, based on an analysis of the single-crystal structure of 1-Z (Figure S47) that the absence of $\pi-\pi$ interactions is responsible for the unusual emission observed in the solid-state. Unfortunately, we could not grow suitable crystals of 1-E for analysis. 

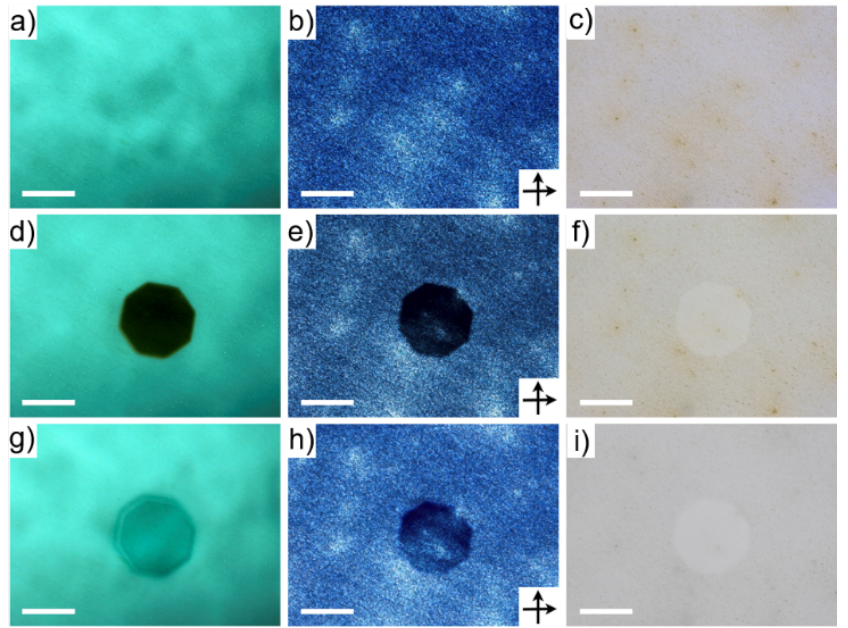

Figure 3. Optical micrographs obtained with 360-nm excited fluorescence (left), cross-polarized (central), and bright field (right) light illumination. ( $a, b, c)$ The as-prepared film; $(d, e, f)$ the film after blue light irradiation $(430-470 \mathrm{~nm})$ in a central spot for $10 \mathrm{~min} ;(\mathrm{g}, \mathrm{h}, \mathrm{f})$ the film in (d, e, f) after near-UV light irradiation $(330-380 \mathrm{~nm})$ in the same central spot for $10 \mathrm{~min}$. Scale bar, $100 \mu \mathrm{m}$. The black arrows in b, $\mathrm{e}$ and $\mathrm{h}$ represent the relative orientation of the polarizer and analyzer.

No changes in the absorption spectrum of the 1-E film were observed after one month at room temperature, proving that the thermal $E$ to $Z$ back isomerization is exceedingly slow in the solidstate. Exposing the 1-E enriched film to $360 \mathrm{~nm}$ light causes spectral changes consistent with $E \rightarrow Z$ photoisomerization $\left(\mathrm{PSS}_{360}=70 \%\right.$ 1-Z; Figure 2). The initial absorption and fluorescence spectra cannot be fully recovered because of the extensive overlap between the absorption spectra of the $E$ and $Z$ forms at $360 \mathrm{~nm}$. Nevertheless, the system displays high fatigue resistance, as its absorption and emission characteristics can be reversibly switched multiple times by alternate irradiation at 450 and $360 \mathrm{~nm}$ (Figure S25). A decrease in the emission intensity is observed after the first switching cycle, which stabilizes in subsequent cycles. This effect might be attributed to an annealing effect (e.g., reorganization of the solidstate structure) that the film undergoes after the first switching cycle.

To get a better insight into what is happening to the drop casted film upon photoswitching, we imaged it with an epifluorescence polarizing optical microscope. The film exhibits a strong fluorescence emission when excited with $360 \mathrm{~nm}$ light (Figure 3a), and significant optical birefringence under cross-polarized light illumination (Figure $3 \mathrm{~b}$ ), confirming an ordered arrangement of the molecules in the solid that gives rise to anisotropic crystals. Upon irradiation with high intensity blue light in a central spot, the morphology of the film changes (Figure 3c-f) and both the optical birefringence (Figure 3e) and fluorescence emission (Figure 3d) disappear in the irradiated area. This observation suggests that isomerization induces a phase transition leading to amorphization of the material. The emission intensity and birefringence of the material are partially restored upon irradiation with high intensity near-UV light. This result confirms the reversible nature of the light-induced switching process and rules out local thermal effects as the cause of the observed phenomenon.

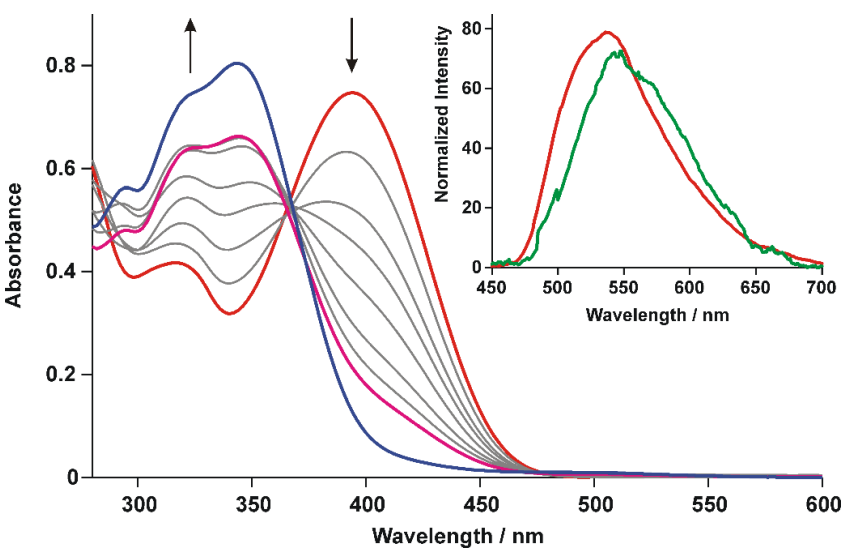

Figure 4. Absorption spectral changes of a toluene solution of 1- $Z$ (red line) upon irradiation at $800 \mathrm{~nm}$ for $3 \mathrm{~h}$ (purple line) and successive rest in the dark for $3 \mathrm{~d}$ (blue line). Inset: emission spectra of $1-Z$ in solution (red line) and in a solid film (green line) upon excitation at 800 $\mathrm{nm}$.

We also investigated the two-photon absorption properties of $\mathbf{1}$ in both solution and solid-state. Indeed, the relevant excited-state manifestations of $\mathbf{1}$ - namely, luminescence and isomerization can be triggered by the absorption of two near infrared photons (i.e., 750 and $800 \mathrm{~nm}$ ), similarly to what we observed upon conventional one-photon excitation. This property is also highly unusual, considering that most small molecules have negligible 2-photon absorption, and that our compound was not specifically designed for this purpose (Figure 4, Figures S56-S59). The absorption crosssection of $1-Z$ in toluene at $800 \mathrm{~nm}$ was measured to be $13.9 \mathrm{GM}$, which is comparable to other photo-switches and slightly lower than spiropyran. ${ }^{28}$

Finally, to demonstrate how easily $\mathbf{1}$, and its solution and solidstate properties can be taken advantage of, and as a proof of concept, we devised two simple experiments (Figures S49 and S54). In the first one a laser pointer was used to reversibly draw sustained structures in a toluene solution of $\mathbf{1}$ (Video S1). The other is a "sketch-and-etch" type application where a laser pointer is used to write on a hydrazone covered transparency slide (Video S3), while $\mathrm{UV}$ is used to erase the writing.

In conclusion, we developed an easy-to-make photochromic hydrazone that features configurational switching and fluorescence toggling with one- or two-photon irradiation in solution (organic and aqueous solutions including serum) and solid-state; the toggled state is stable for years in the dark at rt. All these properties are unprecedented for an individual compound! The combination of the desirable characteristics of several families of photochromic species in a single, easily accessible system, will enable the development of new adaptive functions and systems. For example, the simple molecular structure of $\mathbf{1}$, that does not require additional structural manipulation for it to be emissive ${ }^{29}$ or introduced to water, ${ }^{30}$ can open the way for theranostics, ${ }^{31}$ where diagnostics (by following the distribution and localization of the drug using superresolution fluorescence microscopy ${ }^{32}$ ) and therapy (using photopharmacology ${ }^{33}$ ) are combined.

\section{ASSOCIATED CONTENT}

\section{Supporting Information}

The supporting material is available free of charge on ACS Publications Website at DOI: http://pubs.acs.org. 
General methods, experimental procedures, NMR spectra of compounds, photoisomerization studies, kinetic studies, and solution and solid-state emission studies (PDF)

Crystallographic data for $\mathbf{1}-Z$ (CIF)

Crystallographic data for $\mathbf{2}-Z$ (CIF)

Real-time writing in solution (AVI)

Diffusion in solution (AVI)

Real-time writing in solid-state (AVI)

\section{AUTHOR INFORMATION}

\section{Corresponding Author}

*ivan.aprahamian@dartmouth.edu

*alberto.credi@unibo.it

\section{Author Contributions}

\# B.S., M.B. and H.Q. contributed equally.

\section{Notes}

The authors declare no competing financial interest.

\section{ACKNOWLEDGMENT}

This work was supported by the NSF DMR (DMR-1506170), the European Research Council (grant agreement No. 692981), and the Università di Bologna. We gratefully acknowledge Prof. Richard Staples (Michigan State University) for the X-ray crystallography data.

\section{REFERENCE}

(1) (a) Durr, H.; Bouas-Laurent, H. eds. Photochromism: Molecules and Systems, Elsevier Science, Amsterdam, 2003; (b) Russew, M.-M.; Hecht, S. Adv. Mater. 2010, 22, 3348-3360; (c) Szymanski, W.; Beierle, J. M. H.; Kistemaker, A. V.; Velema, W. A.; Feringa, B. L. Chem. Rev. 2013, 113, 6114-6178; (d) Fihey, A.; Perrier, A.; Browne, W. R.; Jacquemin, D. Chem. Soc. Rev. 2015, 44, 3719-3759; (e) Tian, H.; Zhang, J. eds. Photochromic Materials: Preparation, Properties and Applications, Wiley-VCH, Weinheim, Germany, 2016

(2) (a) Kramer, R. H.; Mourot, A.; Adesnik, H. Nat. Neurosci. 2013, 16, 816-823; (b) Gautier, A.; Gauron, C.; Volovitch, M.; Bensimon, D.; Jullien, L.; Vriz, S. Nat. Chem. Biol. 2014, 10, 533-541.

(3) (a) Yagai, S.; Kitamura, A. Chem. Soc. Rev. 2008, 37, 1520-1529; (b) Ercole, F.; Davis, T. P.; Evans, R. A. Polym. Chem. 2010, 1, 37-54.

(4) (a) Klajn, R.; Stoddart, J. F.; Grzybowski, B. A. Chem. Soc. Rev. 2010, 39, 2203-2237; (b) Pathem, B. K.; Claridge, S. A.; Zheng, Y. B.; Weiss, P. S. Annu. Rev. Phys. Chem. 2013, 64, 605-630.

(5) Blanco, V.; Leigh, D. A.; Marcos, V. Chem. Soc. Rev. 2015, 44, $5341-5370$

(6) (a) Berkovic, G.; Krongauz, V.; Weiss, V. Chem. Rev. 2000, 100, 1741-1754; (b) Kawata, S.; Kawata, Y. Chem. Rev. 2000, 100, 1777-1788.

(7) Szacilowski, K. Chem. Rev. 2008, 108, 3481-3548.

(8) Broichhagen, J.; Frank, J. A.; Trauner, D. Acc. Chem. Res. 2015, 48, 1947-1960.

(9) (a) Feringa, B. L.; Browne, W. R. eds. Molecular Switches, WileyVCH, Weinheim, Germany, 2011; (b) Kassem, S.; van Leeuwen, T.; Lubbe, A. S.; Wilson, M. R.; Feringa, B. L.; Leigh, D. A. Chem. Soc. Rev. 2017, 46, 2592-2621; (c) Stoddart, J. F. Angew. Chem. Int. Ed. 2017, 56, 11094-11125; (d) Sauvage, J-P. Angew. Chem. Int. Ed. 2017, 56, 1108011093; (e) Feringa, B. L. Angew. Chem. Int. Ed. 2017, 56, 11060-11078.

(10) Bandara, H. M. D.; Burdette, S. C. Chem. Soc. Rev. 2012, 41, 1809 1825.

(11) Irie, M.; Fukaminato, T.; Matsuda, K.; Kobatake, S. Chem. Rev. 2014, 114, 12174-12277.
(12) Klajn, R. Chem. Soc. Rev. 2014, 43, 148-184.

(13) Yokoyama, Y. Chem. Rev. 2000, 100, 1717-1739.

(14) (a) Yang, Y.; Hughes, R. P.; Aprahamian, I. J. Am. Chem. Soc. 2012, 134, 15221-15224; (b) Helmy, S.; Leibfarth, F. A.; Oh, S.; Poelma, J. E.; Hawker, C. J.; de Alaniz, J. R. J. Am. Chem. Soc. 2014, 136, 8169-8172; (c) van Dijken, D. J.; Kovaříček, P.; Ihrig, S. P.; Hecht, S. J. Am. Chem. Soc. 2015, 137, 14982-14991; (d) Kobayashi, Y.; Mutoh, K.; Abe, J. J. Phys. Chem. Lett. 2016, 7, 3666-3675; (e) Hammerich, M.; Schu“tt, C.; Sta“hler, C.; Lentes, P.; Ro"hricht, F.; Ho" ppner, R.; Herges, R. J. Am. Chem. Soc. 2016, 138, 13111-13114; (f) Petermayer, C.; Dube, H. Acc. Chem. Res. 2018, 51, 1153-1163; (g) Harris, J. D.; Moran, M. J.; Aprahamian, I. Proc. Natl. Acad. Sci. USA 2018, DOI: 10.1073/pnas.1714499115.

(15) (a)Wegner, H. A. Angew. Chem. Int. Ed. 2012, 51, 4787-4788; (b) Bléger, D.; Hecht, S. Angew. Chem. Int. Ed. 2015, 54, 11338-11349.

(16) (a) Yang, Y.; Hughes, R. P.; Aprahamian, I. J. Am. Chem. Soc. 2014 136, 13190-13193; (b) Qian, H.; Wang, Y.-Y.; Guo, D.-S.; Aprahamian, I. J. Am. Chem. Soc. 2017, 139, 1037-1040; (c) Qian, H.; Pramanik, S.; Aprahamian, I. J. Am. Chem. Soc. 2017, 139, 9140-9143; (d) Qian, H.; Shao, B.; Aprahamian, I. Tetrahedron 2017, 73, 4901-4904; (e) Li, Q.; Qian, H.; Shao, B.; Hughes, R. P.; Aprahamian, I. J. Am. Chem. Soc. 2018, DOI: 10.1021/jacs.8b07612.

(17) (a) Foy, J. T.; Ray, D.; Aprahamian, I. Chem. Sci. 2015, 6, 209-213; (b) Qian, H.; Aprahamian, I. Chem. Commun. 2015, 51, 11158-11161; (c) Pramanik, S.; Aprahamian, I. J. Am. Chem. Soc. 2016, 138, 15142-15145; (d) Aprahamian, I. Chem. Commun. 2017, 53, 6674-6684.

(18) (a) Zhang, Y.; Swaminathan, S.; Tang, S.; Garcia-Amoro's, J.; Boulina, M.; Captain, B.; Baker, J. D.; Raymo, F. M. J. Am. Chem. Soc. 2015, 137, 4709-4719; (b) Beaujean, P.; Bondu, F.; Plaquet, A.; Garcia-Amoro's, J.; Cusido, J.; Raymo, F. M.; Castet, F.; Rodriguez, V.; Champagne, B. J. Am. Chem. Soc. 2016, 138, 5052-5062; (c) Tang, S.; Zhang, Y.; Dhakal, P.; Ravelo, L.; Anderson, C. L.; Collins, K. M.; Raymo, F. M. J. Am. Chem. Soc. 2018, 140, 4485-4488; (d) Zhang, Y.; Tang, S.; Thapaliya, E. R.; Sansalone, L.; Raymo, F. M. Chem. Commun. 2018, 54, 8799-8809.

(19) (a) Zhu, M.-Q.; Zhu, L.; Han, J. J.; Wu, W.; Hurst, J. K.; Li, A. D. Q. J. Am. Chem. Soc. 2006, 128, 4303-4309; (b) Tian, Z.; Wu, W.; Wan, W.; Li, A. D. Q. J. Am. Chem. Soc. 2009, 131, 4245-4252; (c) Li, C.; Zhang, Y.; Hu, J.; Cheng, J.; Liu, S. Angew. Chem. Int. Ed. 2010, 49, 5120-5124.

(20) The absorption diminishes by $10 \%$ after 10 cycles in toluene, however, no changes in absorption are observed in aqueous solutions of $\mathrm{MeOH}$.

(21) We hypothesize that the fluorescence emission results from excited state intramolecular proton transfer, coupled with charge transfer (Figures S38 and S39): Demchenko, A. P.; Tang, K.-C.; Chou, P.-T. Chem. Soc. Rev. 2013, 42, 1379-1408.

(22) (a) Peng, X.; Aratani, N.; Takagi, A.; Matsumoto, T.; Kawai, T.; Hwang, I.-W.; Ahn, T. K.; Kim, D.; Osuka, A. J. Am. Chem. Soc. 2004, 126, 4468-4469; (b) Yamamura, T.; Suzuki, Shingo; Taguchi, T.; Onoda, A.; Kamachi, T.; Okura, I. J. Am. Chem. Soc. 2009, 131, 11719-11726; (c) Crawford, S. E.; Andolina, C. M.; Smith, A. M.; Marbella, L. E.; Johnston, K. A.; Straney, P. J.; Hartmann, M. J.; Millstone, J. E. J. Am. Chem. Soc. 2015, 137, 14423-14429; (d) Jung, H. S.; Lee, J.-H.; Kim, K.; Koo, S.; Verwilst, P.; Sessler, J. L.; Kang, C.; Kim, J. S. J. Am. Chem. Soc. 2017, 139, 9972-9978.

(23) (a) Roubinet, B.; Bossi, M. L.; Alt, P.; Leutenegger, M.; Shojaei, H.; Schnorrenberg, S.; Nizamov, S.; Irie, M.; Belov, V. N.; Hell, S. W. Angew. Chem. Int. Ed. 2016, 55, 15429-15433; (b) Xiong, Y.; Vargas Jentzsch, A.; Osterrieth, J.; Sezgin, E.; Sazaranovich, I. V.; Reglinski, K.; Galiani, S.; Parker, A. W.; Eggeling, C.; Anderson, H. L. Chem. Sci. 2018, 9, 30293040.

(24) (a) Schonbrunn, E.; Eschenburg, S.; Luger, K.; Kabsch, W.; Amrheini, N. Proc. Natl. Acad. Sci. USA 2000, 97, 6345-6349; (b) Amdursky, N.; Kundu, P. K.; Ahrens, J.; Huppert, D.; Klajn, R. ChemPlusChem 2016, $81,44-48$.

(25) a) Koshima, H.; Ojima, N.; Uchimoto, H. J. Am. Chem. Soc. 2009, 131, 6890-6891; b) Bushuyev, O. S.; Tomberg, A.; Friscic, T.; 
Barrett, C. J. J. Am. Chem. Soc. 2013, 135, 12556-12559; c) Tomita, A.; Sato, T.; Adachi, S.; Koshihara, S. J. Am. Chem. Soc. 2014, 136, 9158-9164; d) Baroncini, M.; d'Agostino, S.; Bergamini, G.; Ceroni, P.; Comotti, A.; Sozzani, P.; Bassanetti, I.; Grepioni, F.; Hernandez, T. M.; Silvi, S.; Venturi, M.; Credi, A. Nat. Chem. 2015, 7, 634-640.

(26) Birks, J. B. Photophysics of aromatic Molecules, Wiley, London, 1970.

(27) Kashihara, R.; Morimoto, M.; Ito, S.; Miyasaka, H.; Irie, M. J. Am. Chem. Soc. 2017, 139, 16498-16501.

(28) (a) Saita, S.; Yamaguchi, T.; Kawai, T.; Irie, M. ChemPhysChem 2005, 6, 2300-2306; (b) Matczyszyn, K.; Olesiak-Banska, J.; Nakatani, K., Yu, P. Murugan, N. A.; Zalesny, R.; Roztoczyns'ka, A.; Bednarska, J.; Bartkowiak, W.; Kongsted, J.; Ågren, H.; Samoc, M. J. Phys. Chem. B 2015, 119, 1515-1522; (c) Moreno, J.; Gerecke, M.; Dobryakov, A. L.; Ioffe, I. N.;
Granovsky, A. A.; Bléger, D.; Hecht, S.; Kovalenko, S. A. J. Phys. Chem. $B$ 2015, 119, 12281-12288.

(29) Beharry, A. A.; Wong, L.; Tropepe, V.; Woolley, G. A. Angew. Chem. Int. Ed. 2011, 50, 1325-1327.

(30) Mogaki, R.; Okuro, K.; Aida, T. J. Am. Chem. Soc. 2017, 139, $10072-10078$.

(31) Kelkar, S. S.; Reineke, T. M. Bioconjug. Chem. 2011, 22, 18791903.

(32) (a) Sahl, S. J.; Hell, S. W.; Jakobs, S. Nat. Rev. Mol. Cell Biol. 2017, 18, 685-701; (b) Stone, M. B.; Shelby, S. A.; Veatch, S. L. Chem. Rev. 2017, $117,7457-7477$.

(33) Lerch, M. M.; Hansen, M. J.; van Dam, G. M.; Szymanski, W.; Feringa, B. L. Angew. Chem. Int. Ed. 2016, 55, 10978 -10999. 